\title{
PREDICTION OF TRIP SEVERITY BASED ON TRI-AXIAL ACCELEROMETRY IN HEALTHY OLDER ADULTS
}

\author{
Thaiany Pedrozo Campos Antunes, Kirstin P. van Kesteren
}

\begin{abstract}
Introduction: falls among elderly are apublic health problem and fall prevention is of utmost importance. The ability to recovery from a trip or not might be indicative for fall risk. Objective: toanalyse the relationship between trunk accelerations during the initial phase of tripping and the severity of a tripin healthy older adults. Methods: fourteen healthy older adults (65-73 yrs)walked multiple times over a platform with embedded obstacles and were tripped while trunk accelerations were assessed. Supported bodyweight (BW) by a safety harness was used to classify severity of the tripping outcome into high $(>50 \% \mathrm{BW})$ or low $(<50 \% \mathrm{BW})$. Twelve parameters obtained from the acceleration signals and their derivatives (jerk) within the first second after tripping initiation and were divided into three levels of parameter values with equal amount of trials. These low, medium and high values were tested for their association with trip severity in a logistic regression analysis. Results: three acceleration parametersappeared to be significant predictors oftrip severity. High values of minimum anterior-posterior acceleration and minimum vertical jerkshowed lower likelihood of resulting in a high severity trip than in the low values (33\% and $32 \%$, respectively). Medium values of the maximum anterior-posterior accelerationshowed higher likelihood of resulting in a high severity trip than the low values (327\%).Conclusion: high acceleration and jerk peaks detected within the first second after tripping predict a more severe outcome, indicating that trunk tri-axial accelerometryhas the potential to predict the severity oftripping outcome in healthy older adults.
\end{abstract}

Key words: aged, elderly, accidental falls, near-falls, gait.

\section{INTRODUCTION}

Health care is consideredas the diagnosis, treatment, and prevention of disease, illness, injury, and other physical and mental impairments in humans. The health care responsibility extends far beyond practitioners trained in caring for individuals. Public health is a basic component of health care systems that aimsto improve health and quality of life through prevention and treatment of disease and through promotion of healthy behavior ${ }^{1}$.

The international Institute of Medicine identified three core functions to be provided by all public health agencies: 1) Assessment, defined as assessment and monitoring of the health of communities and populations at risk, to identify health problems and priorities, 2) Policy development, defined as formulating public policies, in collaboration with community and government leaders, to solve identified local and national health problems and priorities, and 3) Assurance, defined as assuring that all populations have access to appropriate and cost effective care, including health promotion and disease prevention services, and evaluation of the effectiveness of that care $^{2}$.
Worldwide, the number of people over 60 years is growing faster than any other age group. Because of this, health problems related to ageing also grow. Falls are the leading cause of injury among elderly, the major reason for admission to hospital or a residential setting and account for $40 \%$ of all injury deaths worldwide ${ }^{3}$. Moreover, they are an important cause of serious physical and psychological consequences that reduce the quality of life of patients and caregivers ${ }^{4}$. The economic impact of falls is critical to family, community, society and healthcare ${ }^{3}$, being thus, a public health problem.

Incidence of fall injuries in older adults have markedly increased by $131 \%$ during the last three decadesand if preventive measures are not taken in the immediate future, the number of injuries caused by falls is expected to increase by $100 \%$ over the next 2 decades ${ }^{5}$. There fore, falls prevention and risk identification in the elderly is of utmost importance.

Body-worn sensors, as accelerometers, have currently shown potential for its use for fall detection ${ }^{6-8}$ and fall risk prediction from daily life measurements. However, validation of fall detection

1 Institute Amsterdam, Faculty of Human Movement Sciences, VU University Amsterdam. Corresponding author: thaianycampos@yahoo.com.br

Article based on the Master thesis " Prediction of trip severity based on tri-axial accelerometry in healthy older adults", by Thaiany Pedrozo Campos Antunes and Kirstin van Kersteren, in Human Movement Sciences, supervised by Mirjam Pijnappels, VU University Amsterdam, 2011.

An objective method was developed to predict the severity of tripping outcome in healthy older adults, based on trunk tri-axial accelerometry. This method allows differentiating trips that potentially can result in a fall from those that one can recover from and continue walking. This method may have the potential to, eventually, be used to assess ones fall risk.

Suggested citation: Antunes TPC, Kesteren KP. Prediction of trip severity based on tri-axial accelerometry in healthy older adults. Journal of Human Growth and Development. 25(1): 75-81

Manuscript submitted Jul 08 2014, accepted for publication Nov 292014. 
and fall prediction models require long periods of observation or follow-up to capture sufficient fall incidents. A potential addition would be to detect near-falls.

Although there is not yet a consensus in literature on the definition of "near-falls", a number of studies with self-report systems indicate that near-falls are clinically relevant markers of falls and fall risk ${ }^{8-13}$, worthy of further study. However, objective techniques for quantifying and classifying these events are limited.

Some researches were done using body-worn sensors to assess near-falls ${ }^{14-16}$, Weiss and coworkers ${ }^{14}$ were one of the first to explore signalprocessing methods to detect near-falls based on body-fixed sensor data. Their results demonstrated that a single tri-axial accelerometer placed on an individual's trunk can distinguish near-falls (i.e., a trip) from other stepping patterns (kicking and stepping over obstacles). This study was done while walking on a treadmill. It is known that there are some differences between over-ground and treadmill walking and, as a result, the accelerometer signal is different in these conditions ${ }^{17}$. Furthermore, although Weiss and co-workers used a safety harness to protect their participantsfrom falling, they did not report whether participants would have fallen if they had not worn the harness.

More recent studies ${ }^{15,16}$ used accelerometers and other worn body-sensors to differentiate nearfalls (i.e. imbalance) from falls and activities of daily living. Although accelerometry was proved to accurately detect falls, the accuracy of this devicein distinguishing near-fall events is still controversy.

In theory, every trip can be considered a nearfall. However, the majority of trips do not result in falls ${ }^{18}$. Hence, for near-fall detection in daily life context to be indicative for fall risk, detection methods should be able to objectively differentiate between signals from trips that result in a fall from those that one can still recover from. We therefore aimedto analyse the relationship between trunk triaxial accelerationsduring the initial phase of tripping and the severity of tripping outcome in healthy older adults in an experimental setting, while walking over-ground.

\section{METHODS}

\section{Participants}

A group of 14 older adults between 65 and 73 years old $(M=69$ yrs, $S D=2,5 y r s ; 8$ males, 6 females) participated. They were recruited through an advertisement in a local newspaper. Participants were included when aged between 65 and 75 and able to walk without aids and excluded in case of functional disturbances that could be of influence in the gait pattern, cognitive disorders or fractures in the past 2 years. They ranged in weight from $52.0-97.5 \mathrm{~kg}(\mathrm{M}=75.0 \mathrm{~kg}$, $S D=12.5 \mathrm{~kg}$ ) and in height from $157-189 \mathrm{~cm}$ $(\mathrm{M}=171 \mathrm{~cm}, \mathrm{SD}=8 \mathrm{~cm})$. The study was approved by the local ethical committee according to the Helsink declaration and a written informed consent was obtained of all participants.

\section{Procedures}

Participants, wearing their own walking shoes, walked back and forth over an $8.5 \mathrm{~m}$ platform with embedded obstacles and force plates. They were asked to walk in the middle of the platform at their preferred velocity. The obstacles could appear at different positions at approximately mid swing, on either the left or the right side. They were triggered by a computer-controlled program, based on foot position, during the trials pre-determined by the researcher ${ }^{19}$.

Foot position and walking velocity were determined by optoeletronic markers, placed at both heels of the subject's feet and measured by an Optotraksystem (Northern Digital Inc, Waterloo, Canada). A custom-made strain gauge $1 \times 1 \mathrm{~m}$ force plate with a sample rateof 2000 samples/s was positioned on the left of the obstacles to detect ground reaction forces by the left leg while being tripped on the right side (see figure 1 ). The participants were informed that they would be tripped in one or more walking trials, but they were unaware of the timing, location, or mechanisms involved for tripping.

A safety harness around the participants' trunk, attached by ropes and dampers to a cart on a ceiling-mounted rail, prevented falling if the

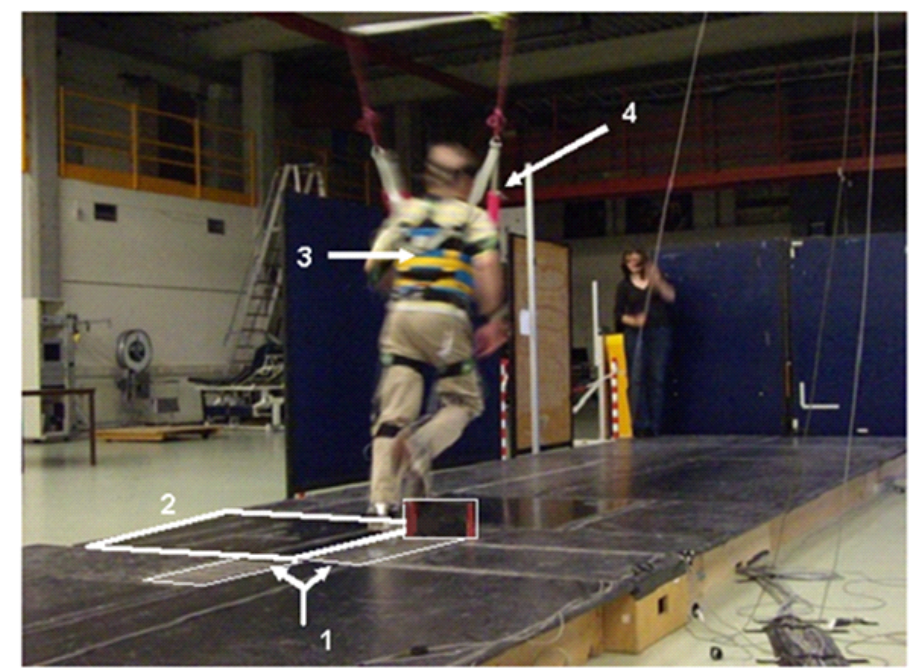

Measurement setup, where 1 = obstacles, 2 = force plate, 3 = accelerometer underneath the safety harness, 4 = safety harness. 
participant was unable to regain their balance when tripped. The safety ropes provided enough slack for unrestrained motion, and a spring, in series with the ropes, ensured smooth restraint in case of a fall ${ }^{19}$. A linear force transducer $(200 \mathrm{~kg}$ range, 2000 samples/s) in the harness ropes measured the body weight support that the participants transferred onto the harness when tripped.

A Dynaport ${ }^{\circledR}$ MiniMod portable tri-axial accelerometer (McRoberts, The Hague, the Netherlands), with a frequency of $100 \mathrm{~Hz}$ and a range of $\pm 6 \mathrm{~g}$, was worn at the height of the $10^{\text {th }}$ thoracic vertebrae to fit with the safety harness.

The participants walked at least 8 times over the platform to get used to the setting before the first trip. Each subject was tripped six to fifteen times depending on their willingness to continue $(M=9.0, S D=2.5$ times $)$ and walked between 49 and 82 times $(M=68.5, S D=10.42$ times) in total.

\section{Data analysis}

The data was processed using MATLAB (The MathWorks Inc., Natrick, MA, USA). The signal of the accelerometer was filtered using a low-pass fourth-order Butterworth filter with a cut-off frequency of $20 \mathrm{~Hz}$. The tripping segments were extracted from the entire data for the analysis (see figure $2 a$ and $b$ ). The signal of the force transducer was converted into percentage of total bodyweight (\%BW) that was supported by the safety harness.

In order to synchronize the frequency of acceleration and force signals, first the foot contacts were detected in the acceleration signal based on the method of Zijlstra and Hof ${ }^{20}$. Medio-

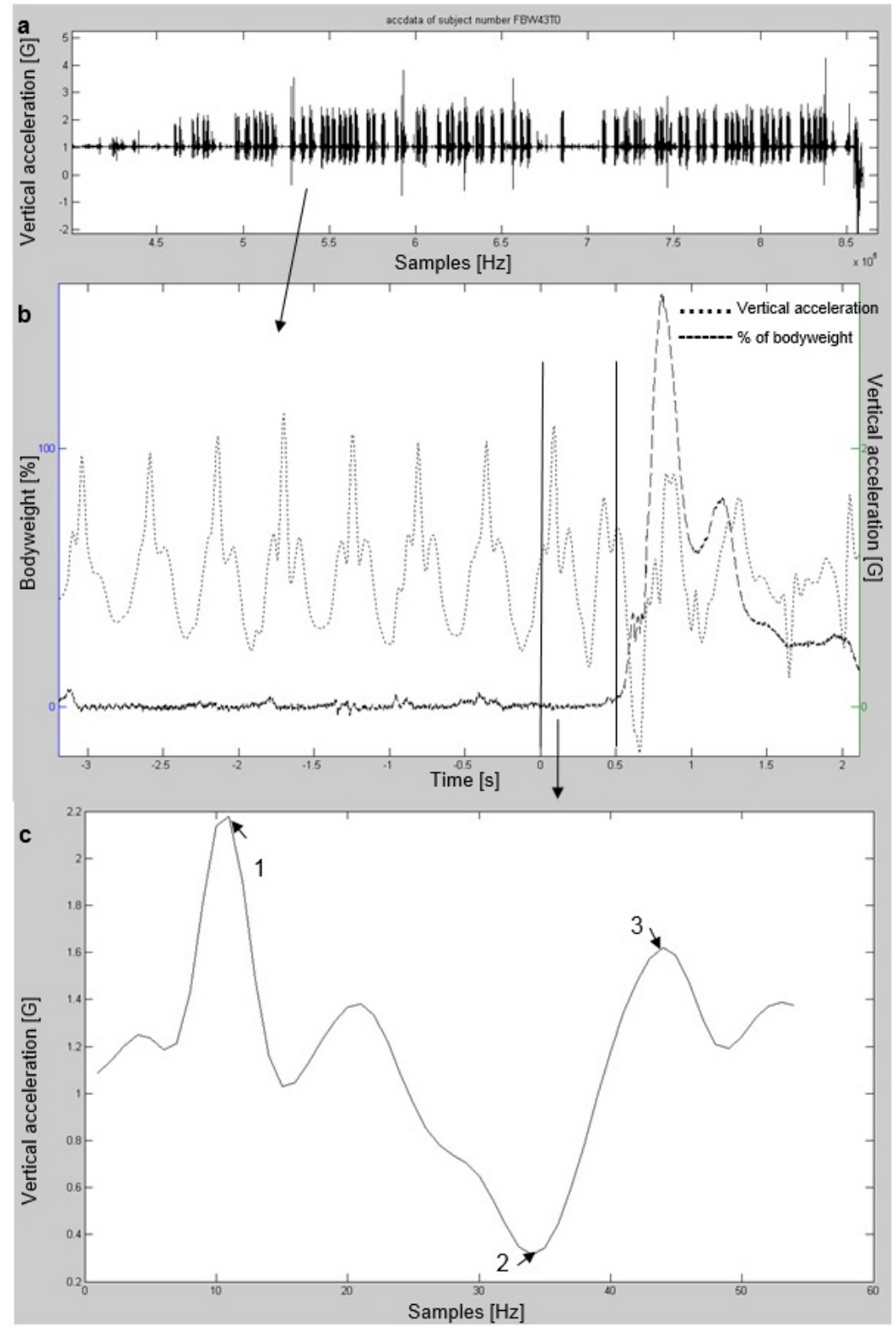

Figure 2: Vertical acceleration signalsof one typical example; (a) for the entire session; (b) for one trial when walking and being tripped, the acceleration is the dotted line, the percentage of bodyweight (\%BW) is the dashed line and time $0 \mathrm{~s}$ is the instant of the last heel strike before tripping; vertical lines indicate the timeframe utilized for the analysis, from the last left heel strike before tripping until the sample where the force on the harness exceeded five \%BW, as zoomed infor (c), where the parameters utilized are pointed out: 1 = maximum vertical acceleration (vmax), $2=$ minimum vertical acceleration $(\mathrm{vmin}), 2-3=$ maximal peak to peak difference of the vertical acceleration $(\mathrm{vmaxp} 2 \mathrm{p})$. 
lateral trunk accelerations were used to differentiate left and right steps before tripping and the data of the force plate was used to detect the last left heel strike beforetripping. This way, forces (force plate and harness force)were synchronized withthe acceleration data (figure $2 \mathrm{~b}$ ). Due to the absence of a force plate to detect the last step before the left trips, all the left trips were excluded. Three right-sided tripping trials were excluded because ofsignal errors.From the remaining trials, the time frame from the last left heel strike before tripping until the sample where the force on the harness exceeded five \%BW was extracted for further analysis (see figure $2 b$ ). This end point was chosen to exclude acceleration signals induced by the safety harness. The five $\%$ BW was considered as a threshold because the force in the harness was always below this value during normal walking, but not during tripping.

In order to explore associations between accelerations and trip severity outcome, twelve parameters were calculated from the vertical and anterior-posterior (AP) acceleration signals within the abovementioned time frame: minimum, maximum and maximum peak to peak acceleration amplitude of vertical (Avmin, Avmax and Avmaxp2p, respectively; figure 2c) and AP (Aapmin, Aapmax and Aapmaxp2p, respectively, ) trunk acceleration and their derivatives (jerk) (Jvmin, Jvmax, Jvmaxp $2 p$, Japmin, Japmax and Japmaxp2p, respectively). For more details on these 12 resulting acceleration parameters see Weiss et $\mathrm{al}^{14}$.

\section{Statistics}

PASW Statistics version 18.0 was used to perform statistical analysis.First, supported bodyweight by the safety harness was used to classify severity of tripping outcome into high ( $>50 \%$ BW) or low ( $<50 \%$ BW). Then, each of the twelve acceleration parameters wasdivided in three levels of categories with equal amount of trials: low, medium and high parameter values.

For each of the acceleration parameters, these low, medium and high values of were tested for their relationship with trip severity as the dependent variable in a logistic regressionanalysis, using Generalized Estimating Equation (GEE) models. The GEE model was used because it allowed to account for within-subject differencesin number of trials and tripping responses. As we expected that the likelihood of having a more severe trip would increase with higher acceleration levels, low categorieswereused as reference.

Acceleration and force sensor data were checked for normality and outliers through boxplots. For each outlier, we checked whether it changed the logistic regression coefficients by $>10 \%$, and if so, they were considered outliers and excluded for further analysis. The averaged walking velocity for each subject and the time frame observed in each trial were added as covariates. If adding either of them changed the regression coefficients by $>10 \%$, they were considered confounders and added to the regression model. The significance level was set at $\mathrm{a}=0,05$.

\section{RESULTS}

In total, 102 right trips were analysed, of which one outlier in the force data was found, therefore 101 trials were included in the statistical analysis, from which 33 trips of each acceleration parameter were in the "low values" category, 34 in the "medium values" category and 34 in the "high values" category. In terms of trip severity, 72 trips were classified as "low severity" and 29 as "high severity". The mean and standard deviation of \%BW relied on the safety harness per category, walking velocity and time frame analysed are shown in table 1.

Table 1: Mean and standard deviation (SD) of the percentage of bodyweight supported by the harness(\%BW) per trip severity category, walking velocity and time frame observed

$\begin{array}{llc} & \text { Mean } & \text { SD } \\ \text { \% BW in low severity } & 29.87 & 9.97 \\ \text { \% BW in high severity } & 73.46 & 15.84 \\ \text { velocity } & 5.06 \mathrm{~km} / \mathrm{h} & 0.34 \mathrm{~km} / \mathrm{h} \\ \text { time frame } & & 116.9 \mathrm{~ms}\end{array}$

Three acceleration parametersappeared significant predictors of trip severity outcome and provided good fit to the data according to Wald Chisquared tests: the "high values" category of Aapmin andJvmin, and the "medium values" category of
Aapmax (table 2). When adding both averaged walking velocity for each subject and the time frame utilized in each trial in the model, the regression coefficients changed by $>10 \%$, hence they were both considered confounders. 
Table 2: Logistic Regression Analysis: statistical tests of independent variables and overall evaluation model

\begin{tabular}{|c|c|c|c|c|c|}
\hline Parameters & categories & OR & $95 \% \mathrm{CI}$ & $\mathbf{p}$ & $\begin{array}{c}\text { Model evaluation } \\
\mathbf{p}\end{array}$ \\
\hline & low & 1 & 1 & & \\
\hline \multirow[t]{3}{*}{ Aapmin } & medium & 2.20 & $0.69-7.01$ & 0.180 & $<0.001$ \\
\hline & high & 0.33 & $0.16-0.66$ & 0.002 & \\
\hline & low & 1 & 1 & & \\
\hline \multirow[t]{3}{*}{ Aapmax } & medium & 3.27 & $1.28-8.37$ & 0.014 & 0.046 \\
\hline & high & 1.40 & $0.66-2.98$ & 0.382 & \\
\hline & low & 1 & 1 & & \\
\hline \multirow[t]{2}{*}{ Jvmin } & medium & 0.69 & $0.31-1.54$ & 0.366 & 0.019 \\
\hline & high & 0.32 & $0.11-0.97$ & 0.044 & \\
\hline
\end{tabular}

Aapmin = minimum anterior-posterior acceleration; Aapmax = maximum anterior-posterior acceleration; Jvmin $=$ minimum vertical jerk; $\mathbf{p}=$ probability value $(<0.05) ; \mathbf{O R}=$ Odds ratio; $\mathbf{C I}=$ confidence intervals.

Aapmin. According to this model, the odds of the high values of Aapmin to result in a high severity trip is lower $(O R=0,33)$ than the low values, indicating that the likelihood of trials with more negative peaks in AP acceleration to result in a trip outcome of high severity is $67 \%$.

Aapmax. According to this model,the odds of the medium values of Aapmax to result in a high severity trip is higher ( $O R=3,27$ ) than the low values. In other words, the likelihood of trials with more medium values of Aapmaxto result in a trip outcome of high severity is $327 \%$, i.e., the likelihood of the medium values of Aapmaxresulting in a trip of high severity is 3,27 times higher than of the low values.

Jvmin. According to this model, the odds of the high values of Jvmin to result in a trip of high severity is lower $(O R=0,32)$ than the low values, indicating thatthe likelihood of trials with more negative vertical jerk values to result in a trip outcome of high severity is $68 \%$.

\section{DISCUSSION}

We aimed to explore whether trunk tri-axial accelerometry can predict the severity of tripping outcome in healthy older adults while walking overground. Logistic regression analysis indicated that Aapmin, Aapmax and Jvmin might be individually used as predictors of a more severe trip. In line with our hypothesis, Aapmin and Jvmin predictors suggested that the higher acceleration amplitudes are more likely to result in a trip with high severity. However, for Aapmax the medium category seems to better predict a high severity trip.

From the few studies that have used accelerometers to assess near-falls ${ }^{15,16}$, Weiss et al. ${ }^{14}$ were one of the first. Their results indicated that the maximum peak to peak difference in vertical jerk was the best single parameter to distinguish a near-fall from a non-fall. This parameter appeared not to distinguish trips with high severity from low severity trips in our data. On the other hand, they did not find Aapmin, Jvmin or Aapmax to be associated with trips.

These discrepancies might be explained by several differences between studies. First, our study population consisted of older adults only, whereas in Weiss' study ten young and five older adults participated. As older people have a slight delay in the activation of some support limb muscles during tripping compared to young subjects ${ }^{21}$, in Weiss' study the young adults could have had a different reaction compared to elderly, masking the reaction of the oldergroup alone. Second, we used shorter time frames than Weiss et al. to calculate the parameters, as we observed that the safety harness always had some effect on the subject's trunk accelerationsafter about 1 second. As the ultimate goal of this study is to explore the potential of accelerometry to assess near-falls in daily-life to, eventually, access fall risk, the acceleration signal induced by the safety harness could not be taken into consideration. Third, as Weiss et al. ${ }^{14}$ aimed to differentiate tripping signals from other reactions signals, they put obstacles in their subjects' path that sometimes could be avoided. More recent studies $^{15,16}$, also used accelerometers and other worn body-sensors to assess near-falls, but aiming to differentiate them (i.e. imbalance) from activities of daily living.In our study, tripping trials were not compared to other stepping patterns, but the differences within tripping outcomes were compared to each other.

Apart from the different methods and predictors that were considered to be good in these studies ${ }^{14-16}$, all of our studies did find that the analysis of trunk acceleration may have the potential for evaluating the fall risk.

There are some limitations in our study that need to be considered. First, it might be argued that the time frame observed was too short to calculate parameters in acceleration that are considered to be reliable predictors of the severity of the trip outcome. However, previoustripping studies showed that the average duration of a normal gait cycle is $1.03 \mathrm{~s}$ and this time increases to on average 1.26 s during tripping ${ }^{22}$. Moreover, an increase in support limb joint moments during the first $60 \mathrm{~ms}$ after the impact with the obstacle already bring about the necessary push-off reaction to restrain the forward rotation of the body, contributing for an adequate recovery ${ }^{21,22}$. These findings support the idea that significant changes intrunk acceleration during a small time frame from 
obstacle contact until recovery initiation could be expected, as confirmed by our results.

It is not fully clear what the predictors found here represent in the time frame observed.The severity of the impact with the obstacle and the subject's reaction to recover could both determine the peak values. For the anterior-posterior parameters, for instance, Aapmax could represent the forward acceleration of the trunk due to the impact of the swing leg with the obstacle, while Aapmin could represent the trunk's backward accelerationin the early stage of the recovery as an attempt to keep the neutral position. As for the representation of the medium values of Aapmax, the subjects possiblyhad just slight forward trunk acceleration with a fast, but exaggerated, backward response resulting, therefore, in a high severity trip. We did not take into account the betweensubjects' ability to react to the trip, which might have been different and masked the effect of the impact with the obstacle on trunk acceleration. For example, two participants may have the same impact with the obstacle, but one is able to recoverbetter than the other, even though the same severity of the trip would be predicted in both cases based on tripping acceleration.

We used a safety harness, for ethical reasons, although in real-life situations a safety harness is not present. This limited the time frames for analyses. Moreover, we considered a harness support $>50 \%$ BW to be a high severity trip. Previous studies also used the amount of harness support to classify gait perturbation outcome $20,23-25$, with varying thresholds values between $18.5 \% \mathrm{BW}^{24}$ to $50 \% \mathrm{BW}^{25}$. So far, the only study that explained the standard used to set the threshold considered a peak load cell force $>30 \% \mathrm{BW}$ as a fall ${ }^{23}$. This threshold, however, also depends on the specific

\section{REFERENCES}

1. Atrash K, Carpentier R. The evolving role of public health in the delivery of health care. Rev Jorn Hum Growth and Develop. 2012; 22(3): 396-399.

2. Institute of Medicine. The future of the public's health in the $21^{\text {st }}$ century. The National Academies Press; Washington: 2003.

3. Organization World Health (WHO). Global Report on Falls Prevention in Older Age. WHO, Department of Ageing and Life Course (ACL); 2007.

4. Rezende DAP, Pereira WMP, Schmitt ACB, Pereira ECA, Aldrighi JM. Prevalência de quedas em mulheres após menopausa. Rev Bras Crescimento Desenvolv Hum. 2011; 21(1): 146-155.

5. Kannus P, Palvanen M, Niemi S, Parkkari J. Alarming rise in the number and incidence of fall-induced cervical spine injuries among older adults. J Gerontol A Biol Sci Med Sci. 2007; 62(2): 180-3.

6. Bagalà $F$, Becker C, Cappello A, Chiari L, Aminian K, Hausdorff JM, et al. Evaluation of rope-length setting of the harness system. If we had used a threshold of $30 \%$ BW, much more trips would be classified as a high severity trip and this was not in line with the visual observations we performed during the experiment.

In its explorative context, the type of analysis used in this study was based on the detection of peaks in acceleration and its derivative. Nevertheless, other methods such as calculating area under the curve and calculating sum of vectors were not investigated here and they might be more suitable to predict the severity of the tripping outcome. Furthermore, single predictors were found to be significant; the combination of these parameters might further improve the model, increasing the precision of the prediction.

Future studies are needed, either to define an appropriate time frame for the calculation of these parameters in daily life context or to check whether these parameters are relevant to predict trip severity in a longer time frame and in daily life settings.

\section{CONCLUSION}

Acceleration and jerk peaks within the first second of trip initiation and recoveryprovide predictive information about the severity of trip outcome in healthy older adults, in a laboratory setting.

\section{ACKNOWLEDGMENT}

The VU University Amsterdam for the fellowship opportunity of realizing this experiment in their laboratory, our supervisor and the PhD students that helped us during the experiments and analysis.

Accelerometer-Based Fall Detection Algorithms on Real-World Falls. PLoS One. 2012; 7(5): e37062. Doi: http://dx.doi.org/10.1371/ journal.pone.0037062.

7. Schwickert L, Becker C, Lindemann U, Maréchal C, Bourke A, Chiari L, et al. Fall detection with body-worn sensors: a systematic review. Z Gerontol Geriatr. 2013 - 46(8):706-719. Doi: http://dx.doi.org/10.1007/s00391-0130559-8.

8. Rispens $S M$, van Schooten KS, Pijnappels $M$, Daffertshofer A, Beek PJ, van Dieën JH. Identification of fall risk predictors in daily Life Measurements: gait characteristics' reliability and association with self-reported fall history. Neurorehabil Neural Repair. 2015; 29(1): 54-61. Doi: http://dx.doi.org/10.1177/154596 831453203.

9. Wiles CM, Busse ME, Sampson CM, Rogers MT, Fenton-May J, van Deursen R. Falls and stumbles in myotonic dystrophy. J Neurol Neurosurg Psychiatry. 2006; 77(3): 393-6. Doi: http://dx.doi.org/10.1136/jnnp. 2005. 066258.

10. Stack E, Ashburn A. Fall events described by people with Parkinson's disease: implications 
for clinical interviewing and the research agenda. Physiother Res Int. 1999; 4(3): 190-200.

11. Srygley JM, Herman T, Giladi N, Hausdorff JM. Self-report of missteps in older adults: a valid proxy of fall risk? Arch Phys Med Rehabil. 2009;90(5):786-92. Doi: http://dx.doi.org/ 10.1016/j.apmr.2008.11.007.

12. Teno J, Kiel DP, Mor V. Multiple stumbles: a risk factor for falls in community-dwelling elderly. A prospective study. J Am Geriatr Soc. 1990; 38(12): 1321-5.

13. Leveille SG, Jones RN, Kiely DK, Hausdorff JM, Shmerling RH, Guralnik JM, et al. Chronic musculoskeletal pain and the occurrence of falls in an older population. JAMA. 2009; 302(20): 2214-21. Doi: http://dx.doi.org/10.1001/ jama.2009.1738.

14. Weiss A, Shimkin I, Giladi N, Hausdorff JM. Automated detection of near falls: algorithm development and preliminary results. BMC Res Notes. 2010; 3: 62. Doi: http://dx.doi.org/ 10.1186/1756-0500-3-62.

15. Aziz O, Park EJ, Mori G, Robinovitch SN. Distinguishing near-falls from daily activities with wearable accelerometers and gyroscopes using Support Vector Machines. Conf Proc IEEE Eng Med Biol Soc. 2012; 2012: 5837-40. Doi: http://dx.doi.org/10.1109/EMBC.2012. 6347321.

16. Lee JK, Robinovitch S, Park E. Inertial SensingBased Pre-Impact Detection of Falls Involving Near-Fall Scenarios. IEEE Trans Neural Syst Rehabil Eng. 2014. Doi: http://dx.doi.org/ 10.1109/TNSRE.2014.2357806.

17. Aaslund MK, Moe-Nilssen R. Treadmill walking with body weight support effect of treadmill, harness and body weight support systems. Gait
Posture. 2008; 28(2): 303-8. Doi: http:// dx.doi.org/10.1016/j.gaitpost.2008.01.011.

18. Pavol MJ, Owings TM, Foley KT, Grabiner MD. The sex and age of older adults influence the outcome of induced trips. J Gerontol A Biol Sci Med Sci. 1999; 54 (2): M103-8.

19. Pijnappels $M$, Bobbert $M F$, van Dieën $\mathrm{JH}$. Contribution of the support limb in control of angular momentum after tripping. J Biomech. 2004 Dec; 37(12): 1811-8. Doi: 10.1016/ j.jbiomech.2004.02.038

20. Zijlstra W, Hof AL. Assessment of spatiotemporal gait parameters from trunk accelerations during human walking. Gait Posture. 2003; 18(2): 1-10.

21. Pijnappels M, Bobbert MF, van Dieen JH. Control of support limb muscles in recovery after tripping in young and older subjects. Exp Brain Res. 2005; 160 (3): 326-33. Doi: http:// dx.doi.org/10.1007/s00221-004-2014-y.

22. Pijnappels M, Bobbert MF, van Dieen JH. How early reactions in the support limb contribute to balance recovery after tripping. J Biomech. 2005; 38(3): 627-34. Doi: http://dx.doi.org/ 10.1016/j. jbiomech. 2004.03.029.

23. Yang $F$, Pai YC. Automatic recognition of falls in gait-slip training: Harness load cell based criteria. J Biomech. 2011; 44(12): 2243-9. Doi: h t t p : / / d x.doi.org/10.1016/ j.jbiomech.2011.05.039.

24. You J, Chou Y, Lin C, Su F. Effect of slip on movement of body center of mass relative to base of support. Clin Biomech (Bristol, Avon). $2001 ; 16(2): 167-73$.

25. Brady RA, Pavol MJ, Owings TM, Grabiner MD. Foot displacement but not velocity predicts the outcome of a slip induced in young subjects while walking. J Biomech. 2000; 33(7): 803-8.

\section{RESUMO}

Introdução: quedas em idosos é um problema de saúde pública. Prevenção de quedas e identificação de riscos em idosos são de extrema importância. Habilidade em retomar ou não a marcha após um tropeço pode indicar um risco para queda. objetivo: analisar a relação entre a severidade de desequilíbrios induzidos por obstáculos e a acelerometria tri-axial. Método: quatorze idosos saudáveis (65-73 anos) caminharam múltiplas vezes sobre uma plataforma com obstáculos ocultos que induziam tropeços, enquanto a aceleração e o peso corpóreo eram mensurados. O peso corpóreo suportado pelo colete de segurança foi usado para classificar a severidade do tropeço: alta (>50\%BW) e baixa $(<50 \%$ BW). Doze parâmetros foram obtidos dos sinais de aceleração e suas derivativas durante o primeiro segundo após o tropeço e foram inclusos na regressão logística como preditores para severidade do tropeço. A severidade do desequilíbrio induzido por obstáculos foi considerada como variável dependente, tendo a categoria baixa como referência. Resultados: três parâmetros de aceleração demonstraram ser preditores significantes. Os valores altos da aceleração ântero-posterior mínima e da derivativa vertical mínima demonstraram menor probabilidade de resultar em queda (tropeço severo) que os valores baixos (33\% e $32 \%$, respectivamente). Os valores médios da aceleração ântero-posterior máxima demonstraram uma probabilidade maior de resultar em queda que os valores baixos (327\%). Conclusão: os picos altos de aceleração e suas derivativas detectados no primeiro segundo após um tropeço preveem um resultado mais severo, indicando que a acelerometria tri-axial de tronco pode ser usada para prever a severidade do resultado de um tropeço em idosos.

Palavras-chave: acelerometria, idosos, quedas, desequilíbrio, marcha. 